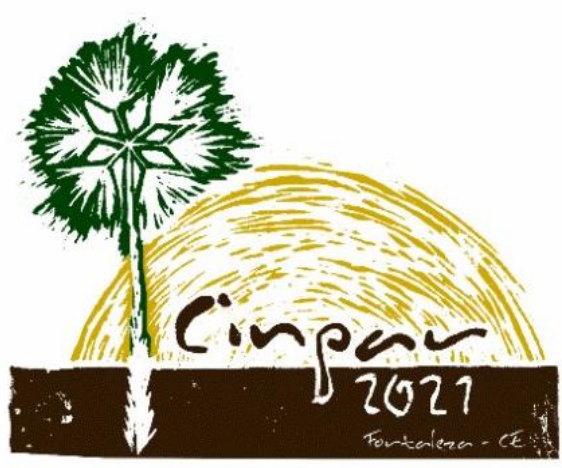

XVII Congresso Internacional sobre Patologia e

Reabilitação das Construções

XVII Congreso Internacional sobre Patología y Rehabilitación de las Construcciones

XVII International Conference on Pathology and Constructions Rehabilitation

FORTALEZA (Brasil), 3 a 5 de junho de 2021

https://doi.org/10.4322/CINPAR.2021.042

\title{
PATOLOGIAS NA CONSTRUÇÃO CIVIL: ESTUDO DE CASO DE UM EDIFÍCIO RESIDENCIAL EM FORTALEZA - CE
} \author{
Raul David de Araújo ${ }^{1}$, Paulo Henrique Bessa Sampaio ${ }^{2}$, Wictor Maia Silveira Rebouças ${ }^{3}$ \\ ${ }^{1}$ Universidade de Fortaleza, Brasil, raul.david.araujo@hotmail.com \\ ${ }^{2}$ Universidade de Fortaleza, Brasil, eng.paulohenrique@edu.unifor.br \\ ${ }^{3}$ Universidade de Fortaleza, Brasil, wyctormaia2000@hotmail.com
}

Pathology in civil construction: Case study of a residential building in Fortaleza - CE

\begin{abstract}
Resumo: Devido a existência de incontáveis falhas na construção civil, às manifestações patológicas estão cada vez mais presente. A evidência desse estudo, tem o propósito maior de apresentar as principais manifestações patológicas de um edifício residencial localizado na cidade de Fortaleza-CE. Em segundo momento, será abordadas possíveis soluções para as patologias mencionadas nesse artigo, baseando-se em livros, publicações de revistas, artigos científicos e pesquisas via internet. Após essa análise, podemos enfatizar que as patologias estão presentes e que necessitam de reparos imediatos feitos por profissionais, visando a segurança e vida útil do edifício.
\end{abstract}

Palavras-chave: Falhas; Manifestações patológicas; Patologias; Construção civil.

\section{Introdução}

A submissão de uma comunicação no Congresso Internacional sobre Patologia e Reabilitação de Estruturas, CINPAR2021, deverá ser realizada através da plataforma online, disponibilizada na página da conferência. Os membros da Comissão Científica irão rever a comunicação submetida propondo uma revisão ou correção, caso seja necessário, antes da aceitação da versão final.

A publicação final do artigo está dependente: (i) da adequada resposta dos autores às propostas de revisão que forem determinadas/recomendadas pelos revisores; (ii) da aceitação do manuscrito submetido pelos autores pela Comissão Científica; e (iii) da inscrição de pelo menos um dos autores do trabalho na Conferência. A apresentação da comunicação terá que ser feita por um autor que esteja inscrito na Conferência.

\section{Instruções gerais}

O texto deverá ser redigido em letra Calibri 11, justificado, com espaçamento 1 entre linhas e 3 (depois) entre parágrafos. Os títulos de parágrafos deverão ser escritos a negrito, ajustados à esquerda, com numeração sequencial, espaçamento simples entre linhas, 18pto antes e 12pto depois.

A partir da 2a página a comunicação deverá incluir em rodapé o título do artigo (se necessário, abreviado) até um máximo de 100 caracteres (incluindo espaços), fonte Calibri 9 itálico, ajustado à esquerda.

Cada comunicação deverá ter um máximo de $\mathbf{2 0}$ páginas. Este limite de páginas inclui resumo, figuras, quadros, agradecimentos e referências bibliográficas. As comunicações que forem fornecidos fora do formato aqui apresentado serão devolvidas para correção.

Algumas regras gerais na elaboração da comunicação: 
- evitar a introdução de linhas em branco na separação entre secções de texto; na maioria dos casos, a formatação adotada para os parágrafos salvaguarda o correto espaçamento do texto;

- não utilizar "tabs";

- alinhar os títulos das secções de texto à esquerda;

- proteger as linhas dos quadros de modo a que fiquem sempre juntas, evitando que o quadro surja partido em páginas diferentes;

- proteger as legendas de quadros e de figuras de modo a que, na página correspondente, surjam sempre acompanhadas do quadro ou da figura a que dizem respeito;

- numerar sequencialmente as páginas da comunicação começando por 1;

- descodificar todas as siglas e acrónimos utilizados na comunicação;

- utilizar o ponto como separador decimal (e.g. 3.1).

\section{Subtítulos}

\subsection{Subtítulo 1}

O subtítulo 1 (espaçamento simples, 12 pto antes, 6 pto depois) é numerado com X.Y não levando qualquer traço nem headings (ou aplicação de estilos).

\subsection{1 - Subtítulo 2}

O subtítulo 2 (espaçamento simples, 12pto antes, 6 pto depois), é numerado com X.Y.Z levando um travessão a seguir à numeração. A formatação não deve incluir headings ou aplicação de estilos.

\subsubsection{1 - Subtítulo 3 (Calibri 11)}

O subtítulo 3 (espaçamento simples, 12pto antes, 6 pto depois) é formatado como acima exemplificado. Contudo, a utilização de muitos níveis de subtítulos pode dificultar a leitura. Estão previstos quatro níveis, mas o ideal é não serem utilizados mais do que três.

\section{Quadros, figuras e equações}

As legendas dos quadros são apresentadas por cima dos mesmos, enquanto as legendas das figuras são colocadas por baixo das mesmas (ver exemplos, fonte Calibri 10, espaçamento simples). Nestas legendas as palavras Quadro, Figura e a respectiva numeração sequencial são escritas a negrito e seguidas de um traço horizontal ( - ). Sempre que um quadro ou uma figura, por não caber inteiramente numa página, passar para a página seguinte, surge um grande espaço em branco no final da página onde o quadro ou a figura estão inseridos. Numa situação destas, os autores deverão procurar reorganizar o texto de modo a evitar o aparecimento de grandes espaços em branco.

Quadro 1 - O quadro deve estar centrado, assim como esta legenda, e não deve levar ponto final. Esta legenda foi formatada impondo indentação de $1 \mathrm{~cm}$, quer à esquerda quer à direita (6pto antes, 3pto depois)

\begin{tabular}{|c|c|c|c|c|}
\hline E & A (cinza 10\%) & B (cinza 10\%) & C & D \\
\hline I & 125 & 123 & 234 & 123 \\
\hline II & 23454,83 & 45425,72 & 2456,00 & 2466,13 \\
\hline III & Aiosi & Ioisio & Iosio & Ziipio \\
\hline
\end{tabular}

Entre o quadro e o texto que segue deve ser introduzida uma linha em branco. $O$ texto dentro do quadro deve aparecer centrado verticalmente relativamente à célula em que se insere. Se a legenda for muito complexa, os autores devem ponderar a sua apresentação no corpo de texto. Se for longa, e em especial se 
ficar muito mais larga do que o quadro ou a figura, deve ser dividida, impondo margens ao texto (caso utilizado na legenda do Quadro acima) ou utilizando o soft enter (em MS Word utilizar Shift+Enter) para dividir o texto por várias linhas, tal como exemplificado na legenda da Figura 1 . As legendas dos quadros e figuras não necessitam de ponto final. Todos os quadros e figuras devem ser referidos no texto, em parágrafos anteriores à sua apresentação. A referência a quadros e figuras deve ser feita por extenso e iniciar com maiúscula (por exemplo, Quadro 1 e Figura 2).

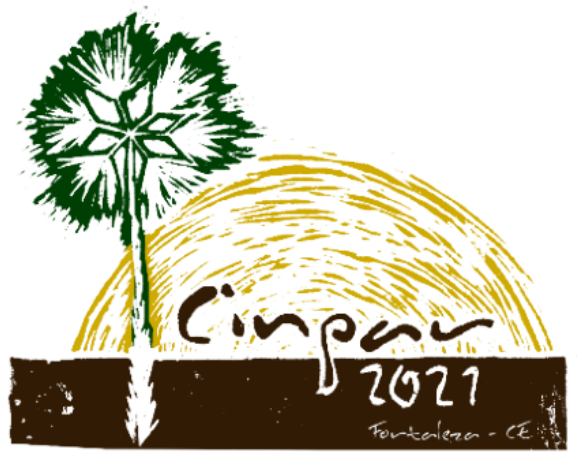

\section{Congresso Internacional sobre Patologia e Reabilitação das Construções}

\section{Congreso Internacional sobre Patología y Rehabilitación de las Construcciones}

\section{International Conference on Pathology and Building Rehabilitation}

FORTALEZA (Brasil), 3 a 5 de junho de 2021

Figura 1 - O CINPAR 2016 representa uma importante oportunidade para a aquisição de novos conhecimentos, técnicas e tecnologias (Calibri 10, 3 pto antes, 6 pto depois)

As figuras não deverão incluir linhas demasiado finas que possam ser impercetíveis. Deverão ser compostas por um único bloco e não por fragmentos gráficos inseridos com o editor de texto.

No layout da figura deve ser selecionada a opção "in line with text" ou "em linha com o texto" para que a sua posição seja mais facilmente controlável.

As equações devem seguir o exemplo abaixo e ser numeradas sequencialmente ao longo da comunicação, sendo a numeração colocada entre parêntesis e alinhada à direita. Para este exemplo foi criada uma tabela (não visível) com três colunas, destinada a incluir a equação e a sua numeração, e que permite alinhar facilmente os elementos mencionados, ou seja, na coluna central colocam-se equações centradas e na coluna da direita coloca-se a numeração alinhada à direita.

$$
y=\sqrt{\frac{a x^{3}+b x^{2}+c x+d}{\sin (x)-\cos (x)}}
$$

Palavras que não sejam portuguesas devem ser formatadas em itálico, tais como software e zoom.

As referências citadas no texto devem incluir o nome dos autores (até um máximo de dois) e a data da sua publicação entre parênteses, como no exemplo que se segue: Alexander (2015); Cutter e Smith (2009). A citação de uma referência bibliográfica que possui mais de dois autores deve incluir apenas o primeiro autor, seguido do texto et al. e da data da sua publicação, como no exemplo que se segue: Oliveira et al. (2012).

\section{Conclusões}

A comunicação deve terminar com um capítulo de conclusões que visa sistematizar as proposições mais importantes do trabalho, destacar as suas principais particularidades e novas contribuições, assim como as suas implicações práticas.

\section{Agradecimentos}

Os eventuais agradecimentos devem ser feitos numa secção separada (título com 18 pto antes, 6 depois), não numerada, antes das referências. 


\section{Referências Bibliográficas}

As referências bibliográficas devem ser organizadas por ordem alfabética e seguir o formato apresentado nesta secção (fonte Calibri 11, espaçamento simples, 3 pto depois, pendente - hanging $-0.5 \mathrm{~cm}$ ). Todas as referências aqui listadas têm que ser referidas no texto da comunicação.

Varum, H., Oliveira, J., Rodrigues, H. (2014). Seismic Behavior of RC Buildings: Lessons of Recent Earthquakes in Europe. International Congress about Pathology and Structures Rehabilitation - CINPAR 2014, Santiago, Chile; june 2014.

Almeida, I.M.F. (2008) Caracterização de Patologias. Tese de Doutoramento. Faculdade de Engenharia, Universidade do Porto, Portugal.

Oliveira, F.H., Rodrigues, E., Sands, D., Branco, M. (2012). Rehabilitation of Existing Reinforced Concrete Structures. Earthq. Eng. \& Struc. Dyn., 21 (1), 1-19. 